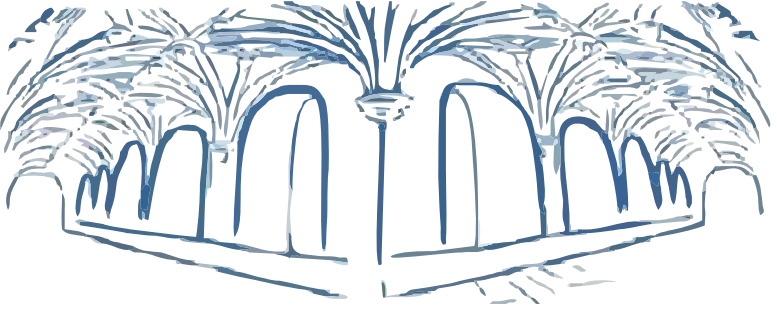

Gonçalves, D.A.R, Nogueira, I.C. (2020).

Reconfiguração da formação de professores em tempos excecionais - COVID19.

Revista Practicum, 5(1), 95-105

DOI: 0.24310/RevPracticumrep.v5i1.9832

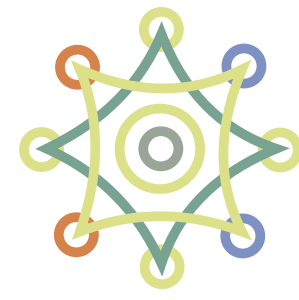

R E V I S T A

PRACTICUM

Número 5(1), Enero-Junio, 2020

ISSN: $2530-4550$

Fecha de recepción: 02-05/2020

Fecha de aceptación: 30-05/2020

\title{
Reconfiguração da formação de professores em tempos excecionais - COVID19
}

\section{Teacher training reconfiguration in exceptional times - COVID19}

\author{
Daniela Alexandra Ramos Gonçalves \\ ESE de Paula Frassinetti \\ daniela@esepf.pt
}

Isabel Cláudia Nogueira

ESE de Paula Frassineti

icn@esepf.pt

\section{Resumo}

Em tempos extraordinários e excecionais - COVID19 - os professores são convidados a lecionar em ambientes de aprendizagem e ensino totalmente novos e com contornos totalmente digitais, a partir de meios, que desafiam o seu exercício profissional docente em todas as etapas da intervenção educativa. Emerge um novo desafio - concretizar uma ação educativa estruturada a partir de algo completamente novo - resultante da impossibilidade de mobilização dos meios e das estruturas mentais do ensino presencial. A partir de 16 de março de 2020, as instituições de ensino portuguesas foram obrigadas a substituir todas as atividades presenciais por atividades à distância, interrompendo-se as aulas presenciais regulares e os estágios em contexto de trabalho.

Neste texto, apresentaremos a forma como, neste atual e ímpar contexto educativo internacional, uma instituição de ensino superior portuguesa procedeu à reconfiguração das atividades de Iniciação à Prática Profissional num curso de formação de professores. 


\section{Abstract}

In extraordinary and exceptional times - COVID19 - teachers are invited to teach in entirely new learning and teaching environments with totally digital outlines, using resources that challenge their professional teaching practice at all intervention educational stages. A new challenge emerges - to implement a structured educational action based on something new - resulting from the impossibility of mobilizing the devices and mental structures of classroom teaching. Since March 16, 2020, Portuguese educational institutions were forced to replace face-to-face activities for distance activities, interrupting all regular classes, as well as internships.

In this text, we will describe how, at the current and unique international educational context, a Portuguese higher education institution proceeded to reconfigure Initiation to Professional Practice activities in a teacher training course.

\section{Palavras-chave}

Formação de professores, iniciação à prática profissional, ambiente de aprendizagem, metodologias de aulas online.

\section{Keywords}

Teacher training, initiation to professional practice, learning environment, online class methodologies.

\section{Formação de Professores na contemporaneidade}

Na Estratégia Europa 2020, a Comissão Europeia estabeleceu como prioridades o crescimento inteligente, o crescimento sustentável e o crescimento inclusivo - Comunicação da Comissão - "Europa 2020: Estratégia para um crescimento inteligente, sustentável e inclusivo" -, procurando assim alcançar uma economia conceptual alicerçada no conhecimento e na inovação, que promova a sua eficiência, nomeadamente quanto à utilização dos recursos com vista à melhoria da coesão social).

Neste contexto, as noções de educação e de aprendizagem, revestem-se de um novo sentido e de uma nova amplitude porque, tal como em outras épocas marcantes, a educação assume agora uma importância estratégica para o desenvolvimento integral do ser humano viabilizando (Aragay, 2017) assim, um crescimento equilibrado e sustentado das sociedades futuras.

A escola tem-se reafirmado como um espaço de referência social e os professores terão de estar dotados de competências que lhes permitam compreender 
as linhas fundamentais dos processos de mudança que afetam o mundo em geral e, em particular, as famílias e a escola. No nosso entender, os professores são agentes ativos da mudança dado que ocupam uma posição privilegiada para responderem, com criatividade, aos desafios que lhes são colocados diariamente (Gonçalves \& Nogueira, 2019). Em simultâneo, além de deverem ser os principais impulsionadores da transformação do sentido das instituições educativas e, no âmbito desta, o das conceções de educação e de ensino, podem ser ainda atores fundamentais na tarefa do desenvolvimento harmonioso e integral de cada ser humano (Carbonell, 2015).

Os reptos que hoje se colocam aos professores convocam-nos a desempenhar tarefas que reclamam uma formação global (Riviere, 2003; Víton de António, 2013; Varela, 2006) que englobe: i) uma vertente científica, de atualização ao nível das áreas de saber; ii) uma vertente pedagógica, de aperfeiçoamento de competências no domínio das didáticas inerentes aos diversos processos e metodologias de ensino-aprendizagem; iii) uma vertente de formação pessoal, de desenvolvimento e alteração de atitudes e cognições, nomeadamente no que diz respeito a aspetos relacionais da interação educativa; iv) uma vertente investigativa e de inovação, tomando como campo privilegiado de análise as situações pedagógicas vivenciadas pelo professor.

Em particular, neste tempo extraordinário e excecional - COVID19 - os professores são convidados a lecionar em ambientes de aprendizagem e ensino totalmente novos, para muitos com contornos totalmente digitais, mas onde a proximidade é possível, a partir de meios, síncronos e assíncronos, que desafiam o seu exercício profissional em todas as etapas da intervenção educativa. Assim, o novo desafio consiste em concretizar uma ação educativa estruturada a partir de algo que é novo, abdicando da mobilização dos meios e estruturas mentais do ensino presencial. Quiça seja realmente o momento de questionarmos a possibilidade de encontrar formas complementares e pertinentes para a formação de professores no presente e no futuro.

Sabendo que o professor deverá possuir qualificações e competências necessárias para o desempenho profissional docente e para a aprendizagem ao longo da vida (Biesta, 2016), considera-se que o projeto de formação que iremos explorar contempla: uma dimensão profissional, social e ética da atividade docente; uma dimensão de desenvolvimento do ensino e da aprendizagem num quadro de uma relação pedagógica de qualidade, integrando, com critérios de rigor científico e metodológico, conhecimentos das áreas que o fundamentam; uma dimensão de participação na escola e de relação com a comunidade; uma dimensão de desenvolvimento profissional ao longo da vida, incorporando a sua formação como elemento constitutivo da prática profissional mediante a análise problematizada da sua prática pedagógica e a reflexão fundamentada sobre a 
construção da profissão, em cooperação com outros profissionais; uma dimensão de investigação e de agente de inovação pedagógica, tendo em conta o papel reflexivo e criador no processo educativo que os professores são chamados a exercer de forma colaborativa (Gonçalves \& Silva, 2017).

Hoje, mais do que nunca, a partilha e a colaboração são ingredientes essenciais às respostas encontradas para que nenhum aluno fique para trás (Beaudoin, 2013) e, ao mesmo tempo, para que todos possam aprender e fazer ensinar com recurso a diferentes dispositivos, plataformas e recursos digitais.

\section{Estratégia educativa implementada no cenário de emergência}

Em Portugal, as instituições de ensino (superior e não superior) foram legalmente obrigadas a proceder à substituição de todas as atividades presenciais por atividades à distância a partir de 16 de março de 2020, interrompendo as aulas presenciais regulares, assim como a realização de estágios em contexto de trabalho (Escolas Cooperantes).

Perante tal acontecimento singular, a Escola Superior de Educação de Paula Frassinetti (ESEPF) desenhou e apresentou à sua comunidade educativa as orientações comuns para a realização de aulas à distância em tempos da pandemia resultante da COVID19. Não houve qualquer hiato entre as aulas presenciais e as aulas à distância, o que resultou do envolvimento de todos os órgãos de gestão, departamentos, equipas de docentes, equipas de técnicos especializados e estudantes, possibilitando a manutenção de um alinhamento estratégico, ainda mais fundamental neste cenário excecional. Em linhas gerais, nesta modalidade de ensino exclusivamente à distância todos os procedimentos comuns assumidos continuaram associados a uma tríade, estrutural e estruturante na ESEPF, articulada com a Missão e Projeto Educativo institucional: Valores, Saberes e Práticas de referência.

Como consequência, o objetivo geral foi ajustar toda a estratégia de ensino - metodologias, recursos, avaliação, ... - das diferentes unidades curriculares a procedimentos não presenciais, conferindo um (ainda) maior investimento às lógicas educativas/formativas contínuas. Neste contexto extraordinário de aprendizagem e de ensino, que exige modelos à distância, formularam-se metodologicamente orientações gerais com a finalidade de garantir o alcance dos resultados de aprendizagem dos alunos e o cumprimento dos conteúdos programáticos definidos em cada uma das unidades curriculares.

Desta forma, do que foi estabelecido no conjunto de procedimentos comuns na relação educativa a distância, na gestão dos objetivos de aprendizagem e nas 
estratégias de avaliação, bem como no uso das tecnologias de suporte a essas mesmas aulas e contactos a distância, destacam-se:

a) a comunicação e a interação regulares com os estudantes deveriam ser regulares e em todas as aulas online deveriam adotar-se as estratégias e as metodologias de ensino mais apropriadas. Para melhor compreensão da realização das tarefas e acompanhamento da aquisição das aprendizagens por parte dos estudantes, cada professor disponibilizaria na unidade curricular do Moodle o plano de aula respetivo e, havendo, os recursos ou tarefas apropriadas ao desenvolvimento da mesma;

b) os conteúdos programáticos e os objetivos de aprendizagem de cada unidade curricular deveriam ser integralmente lecionados e/ou promovidos pelo docente através das aulas a distância;

c) as metodologias de ensino a distância deveriam ser diversificadas, enquadradoras, propiciando a apresentação de exemplos, em benefício da autorreflexão e o trabalho autónomo dos estudantes;

d) o enfoque na promoção e diferenciação de estratégias de ensino e formas de acompanhamento, que permitissem capacitar os estudantes para os resultados da aprendizagem, bem como no uso criativo e apropriado das tecnologias de suporte, especialmente aquelas que permitam realizar produtos avaliativos mais adequados ao objeto e objetivo de cada unidade curricular.

Das tarefas solicitadas aos estudantes, todos os docentes assumiram o compromisso de fornecer feedback sobre o trabalho desenvolvido pelos estudantes (individual, de grupo, turma...), através das suas mais diversas formas e meios (plataforma Moodle, correio eletrónico, reuniões em videoconferência, fóruns de discussão, entre outros), proporcionando-lhes dessa forma a apropriação do seu processo de aprendizagem, tal como é apontado e sugerido como boa prática em diversas teorias públicas (Ferguson et al, 2019).

De forma colaborativa, a estrutura diretiva e o Conselho Pedagógico da ESEPF construíram um instrumento de recolha de informação que permitisse acompanhar em tempo útil o desenvolvimento das atividades letivas desenvolvidas, favorecendo tanto a emergência e partilha de boas práticas adotadas como a identificação de situações merecedoras de eventuais ajustes a modo(s) e/ou tempo(s) a elas alocadas, com a subsequente possibilidade de melhoria.

O instrumento elaborado, materializado sob a forma de questionário eletrónico e de preenchimento simples e rápido, foi disponibilizado na plataforma de apoio à gestão de atividades académicas já há muito utilizada na ESEPF (Moodle). Cada um, dos 26 docentes implicados neste semestre, deveria submeter um questionário referente a cada uma das aulas lecionadas no período acima, estruturado nas seguintes componentes: 
- Identificação da aula (data, curso e unidade curricular a que dizia respeito)

- Indicação do tipo de tarefa(s) proposta(s) para essa aula - a partir de um elenco previamente definindo e/ou explicitando outro tipo de tarefa(s) não contempladas

- Indicação do tempo disponibilizado para a realização das tarefas

- Explicitação do(s) modo(s) de monitorização/acompanhamento do trabalho realizado pelos estudantes

- Quantificação do número de estudantes da turma que foi capaz de realizar a(s) tarefa(s) proposta(s) para essa aula no período definido para a sua concretização.

Na secção seguinte apresentaremos a (re)configuração das atividades da Iniciação à Prática Profissional em 1. Ciclo do Ensino Básico, no âmbito da Licenciatura em Educação Básica, assim como os dados já disponíveis decorrentes da sua monitorização.

\section{O caso da Iniciação à Prática Profissional}

\subsection{Caracterização e organização interna}

A unidade curricular de Iniciação à Prática Profissional do 1. Ciclo do Ensino Básico integra o 2.․ ano do plano de estudos da Licenciatura em Educação Básica e compreende um total de 48 horas, distribuídas por 8 horas de tipologia Seminário, 36 horas de Estágio e 4 horas de Orientação Tutorial.

Para essa unidade curricular, estão definidos como objetivos de aprendizagem:

a) compreender a estrutura e funcionamento das Escolas do 1. Ciclo do Ensino Básico;

b) saber selecionar e aplicar instrumentos de recolha de informação para, numa ótica formativa, proceder à caracterização dos alunos e dos contextos educativos;

c) analisar as diferenças existentes nos atores (professores e alunos) nos diferentes contextos de intervenção em sala de aula, consciencializando-se com a sua orientação profissional;

d) revelar sentido crítico na seleção que faz das fontes de informação;

e) saber relacionar a informação, revelando compreensão pedagógica;

f) identificar perfis diferentes na ação pedagógica ao nível das competências para ensinar e

g) fundamentar, revelando conhecimento pedagógico, a sua opção profissional. 
Para o ano letivo em curso, as atividades a desenvolver ao longo da unidade curricular estavam organizadas como se ilustra na Tabela 1:

\begin{tabular}{|l|l|l|}
\hline \multicolumn{2}{|l|}{ Data } & Tipologia da atividade \\
\hline 12 de fevereiro & Seminário & 2 horas \\
\hline De 17 a 21 de fevereiro & Estágio & 25 horas \\
\hline 26 de fevereiro & Orientação tutorial & 2 horas \\
\hline 4 de março & Seminário & 2 horas \\
\hline 25 de março & Seminário & 2 horas \\
\hline 14 abril & Orientação tutorial & 2 horas \\
\hline De 15 a 17 de abril & Estágio & 11 horas \\
\hline 22 de abril & Seminário & 2 horas \\
\hline
\end{tabular}

Tabela 1. Organização da unidade curricular (elaboração própria).

\subsection{A realidade concretizada}

Até ao dia 4 de março, as diversas atividades decorreram de acordo com os modos previstos. 0 primeiro seminário teve como principal finalidade o enquadramento da unidade curricular, incluindo a explicitação dos seus objetivos, da sua organização interna e da intencionalidade subjacente às diferentes tipologias de aulas/horas definidas para as aprendizagens esperadas; nesse mesmo dia, foi ainda apresentada e justificada a modalidade de avaliação adotada.

No primeiro período de estágio, decorrido entre 17 e 21 de fevereiro, as estudantes experienciaram a realidade quotidiana de uma sala de aula do 1.. Ciclo do Ensino Básico

A primeira sessão de orientação tutorial centrou-se em aspetos relacionados com a elaboração do relatório de estágio, instrumento adotado para a avaliação das aprendizagens atingidas pelas estudantes na unidade curricular, bem como na partilha das perceções iniciais das estudantes face à realidade das Escolas Cooperantes.

A 4 de março ainda as atividades de ensino e aprendizagem decorriam de forma presencial, e foi nesse modo que se realizou o segundo seminário na instituição de ensino, desta vez com um dinamizador convidado e intitulado "Matemática e Magia". Este momento teve como principal finalidade apresentar exemplos de práticas e do quotidiano que envolvem conhecimento matemático.

A suspensão obrigatória de todas as atividades de ensino em todas as instituições portuguesas a partir do dia 16 de março, que impôs a necessidade ur- 
gente de definição de estratégias alternativas à tradicional formação presencial, implicou uma reconfiguração desta unidade curricular, dada a impossibilidade de realização de estágio em contexto real.

Deste modo, a responsável da unidade curricular, em articulação com o Departamento de Formação de Professores e com a diretora do ciclo de estudos, (re)configurou as sessões seguintes tendo como propósito dar continuidade ao processo de aprendizagem e investimento, numa lógica favorável e ao alcance do sucesso de todos os estudantes.

A 25 de março de 2020, através de uma sessão síncrona, realizou-se um seminário dedicado a uma das etapas da intervenção educativa: a avaliação. $O$ conteúdo do seminário englobou vários aspetos relativos à avaliação das aprendizagens, em particular, os fundamentos da avaliação - o que se avalia, como se avalia e para que se avalia -, distinguindo a função formadora e formativa da avaliação, assim como a avaliação sumativa ou certificadora e a avaliação formativa para a melhoria. Neste âmbito, e já na modalidade assíncrona, foi proposto um exercício de planificação e respetiva avaliação, onde os estudantes foram convidados a eleger um indicador de um dos domínios da disciplina de Português das Aprendizagens Essenciais do 1. ou 2. ano do 1. Ciclo, cruzando-o com um ou dois indicadores de uma das áreas do Perfil dos Alunos à Saída da Escolaridade Obrigatória (Ministério da Educação, 2017), implicando essa construção partir desses referenciais uma estratégia de aprendizagem e respetivos elementos de avaliação (instrumentos e critérios). 0 processo de monitorização revelou que esse exercício foi realizado por todos os estudantes, a quem foi fornecido feedback individual processual.

Seguiu-se, a 14 de abril, uma sessão de orientação tutorial na modalidade síncrona, a partir da plataforma Zoom, onde as estudantes, organizadas em grupo por núcleo de estágio, apresentaram a Escola Cooperante onde realizaram o estágio presencial. Todos os grupos realçaram a missão e o projeto educativo da Escola Cooperante, fruto da experiência educativa e análise dos documentos estruturantes: Projeto Educativo, Regulamento Interno, Plano Anual das Atividades e Projeto Curricular de Escola. Para além disso, focaram na apresentação os modos de trabalho pedagógico - organização do trabalho pedagógico, dinâmicas de colaboração entre os docentes, momentos de partilha e negociação, entre outros -, no sentido de aprofundar o conhecimento sobre o futuro exercício profissional. Finalmente, destacaram o(s) elemento(s) diferenciador(es) das respetivas Escolas Cooperantes, elencando iniciativas, soluções e projetos com contornos inovadores e caraterizadores da identidade institucional. Desta vez, o feedback foi fornecido aos grupos e registado no Moodle.

Dando continuidade às atividades de observação em contexto de 1. Ciclo do Ensino Básico, no seminário de 22 de abril (modalidade assíncrona), foi solicitado 
aos estudantes que visualizassem duas aulas do Projeto \#estudoemcasa, disponíveis na página web do Ministério da Educação e da Televisão Portuguesa Estatal, elaborando um relato sobre as estratégias de ensino utilizadas, tendo em conta a especificidade deste nível de ensino. Todas as estudantes realizaram a atividade proposta com êxito e entusiasmo e o feedback foi mais uma vez personalizado, oferecendo pistas de reflexão sobre o modo de integração deste tipo de atividade com a concretização do relatório de estágio.

Para a continuidade da unidade curricular e tendo como critério essencial o sucesso académico de todas as estudantes, respeitando como até aqui os objetivos de aprendizagem definidos na ficha de unidade curricular, foi proposto aos estudantes elaborarem uma análise crítica aos recursos/materiais e roteiro para a implementação do plano de aulas a distância apresentados pelo Ministério da Educação [1] para o ensino do 1.o Ciclo do Ensino Básico, bem como do Projeto \#estudoemcasa [2], contabilizando dessa forma 11horas de estágio, a partir de um guião de aprendizagem construído para o efeito. Esta análise seria incluída no Relatório de Estágio, complementando a recolha de dados decorrente das 25 horas de estágio que os estudantes realizaram presencialmente.

É de salientar que no que diz respeito à estratégia de avaliação da unidade curricular, não existiu a necessidade de proceder a qualquer alteração: a avaliação é de natureza contínua e tem por base a caraterização do contexto de prática, a apresentação da Escola Cooperante, a participação nos seminários de formação e nas orientações tutorias, o relatório de estágio que integra os trabalhos desenvolvidos na Iniciação à Prática Profissional em contexto de 1. Ciclo do Ensino Básico, enquanto representação dos processos de desenvolvimento profissional e pessoal.

\section{Reflexões finais}

A reconfiguração da Iniciação à Prática Profissional em contexto de 1.은 Ciclo do Ensino Básico em tempos excecionais oferece-nos a certeza de que o desenvolvimento profissional docente não equivale à formação de professores: lançar um novo olhar sobre formação de professores, valorizando a sua emancipação pré-profissional, possibilita aos futuros professores deixarem de ser entendidos como meros recetores de informação, passando a ser encarados como pré-profissionais autónomos e responsáveis, com múltiplas facetas e potencialidades próprias. Deste modo, a estratégia adotada apontou para ideias de continuidade, processo e evolução, noções não totalmente compatíveis com uma visão tradicional de justaposição da formação inicial com o aperfeiçoamento préprofissional, proporcionado pela formação contínua.

Recusamos, obviamente, a valorização da formação baseada numa racionalidade técnica que considera os futuros professores meros executores de decisões 
alheias e privilegiamos processos de formação que reconhecem a sua capacidade para assumir posições e tomar decisões. Foi, ainda, preconizado um processo formativo contextualizado, numa perspetiva de desenvolvimento profissional que propiciou o confronto das ações quotidianas dos professores com as teorias públicas, o que consideramos uma excelente oportunidade para os estudantes reverem a sua conceção de prática docente e respetivas teorias que a enformam, numa atitude de sistemática de pesquisa e de procura de novos conhecimentos para a teoria e para a prática de ensinar. Por outras palavras, e tal como defende Moreira, consideramos que

as transformações das práticas docentes só se efectivam à medida que o professor amplia a sua consciência sobre a própria prática, a de sala de aula e a de escola como um todo, o que pressupõe os conhecimentos teóricos e críticos sobre a realidade como inovador edificante - com o objectivo de evidenciar a importância de mobilizar, na prática docente, dispositivos que induzem/ geram/facilitam a análise da acção profissional docente (2010, p.21).

Esta reconfiguração da Iniciação à Prática Profissional em contexto de 1.ㅇ Ciclo do Ensino Básico permitiu, ao mesmo tempo, um investimento no trabalho colaborativo entre docentes do mesmo ciclo de estudos, em particular, e de toda a instituição, em geral, com várias iniciativas que tiveram como pressuposto a partilha o intercâmbio de ideias a propósito de documentação relevante face ao estado de emergência [3], projetos e teorias, o que proporcionou um amadurecimento do alinhamento estratégico institucional, bem como uma proximidade profissional, apesar da distância física decorrente do isolamento social.

\section{Notas}

[1] ROTEIRO - 8 Princípios Orientadores para a Implementação do Ensino a Distância (E@D) nas Escolas https:// www.dge.mec.pt/sites/default/files/roteiro ead vfinal.pdf

[2] O conjunto de conteúdos educativos disponibilizados através do \#EstudoEmCasa estão a ser desenvolvidos numa parceria entre o Ministério da Educação, a RTP e conta com o apoio da Fundação Calouste Gulbenkian (https://estudoemcasa.dge.mec.pt).

[3] Exemplo de documentos analisados pela equipa de docentes: 10 Recomendações sobre o ensino a distância da Unesco (https://news.un.org/pt/story/2020/03/1706691?fbclid=IwAR2dhXPEMN0-KW BERqkgK5ytpWmoOcQTIXF0pKU9fhfwE3XNYfvyAeaiis), OCDE, Education responses to covid-19: Embracing digital learning and online collaboration, 23 de março de 2020 (https://oecd.dam-broadcast.com/pm 7379120 120544-8ksud7oaj2.pdf) 


\section{Referencias bibliográficas}

Aragay, X. (2017). Reimaginando la educación. 21 claves para transformar la escuela. Barcelona: Ediciones Paidós.

Beaudoin, N. (2013). Una Escuela para cada Estudiante. La relación interpersonal, clave del processo educativo. Madrid: Narcea.

Biesta, G. J. (2016). Devolver la enseñanza a la educación. Una respuesta a la desaparición del maestro. Pedagogía y saberes, (44),

119-129.

Carbonell, J. (2015). Pedagogías del siglo XXI. Alternativas para la innovación educativa. Barcelona: Octaedro.

Comunicação da Comissão — «Europa 2020: Estratégia para um crescimento inteligente, sustentável e inclusivo» [COM(2010) 2020 final de 3 de março de 2010]

Ferguson, R., Coughlan, T., Egelandsdal, K., Gaved, M., Herodotou, C., Hillaire, G., Jones, D., Jowers, I., Kukulska-Hulme, A., McAndrew, P., Misiejuk, K., Ness, I. J., Rienties, B., Scanlon, E., Sharples, M., Wasson, B., Weller, M. \& Whitelock, D. (2019). Innovating Pedagogy 2019: Open University Innovation Report 7. Milton Keynes: The Open University.

Gonçalves, D. \& Nogueira, I.C. (2019). Eixos estruturantes do desenvolvimento profissional docente. In N. Fraga (Org.), CIEC 2018 - II Conferência Internacional de Educação Comparada (pp.525-536). Funchal:

\section{CIE-UMa.}

http://repositorio.esepf.pt/ bitstream/20.500.11796/2809/1/Atas $\% 20$ CIEC\%202018\%20DPD.pdf
Gonçalves, D. \& Silva, C.V. (2017). Avaliação da Prática de Ensino Supervisionada na formação inicial de professores. In Atas do XIV Symposium Internacional sobre el praticum y las prácticas externas "Recursos para um Prácticum de Calidad” (pp. 779787). Pontevedra: Andavira Editora. Disponível em http://reppe.org/wp-content/ uploads $/ 2016 / 06 /$ actas $17 . p d f$

Ministério de Educação (2017). O Perfil dos alunos à saída da Escolaridade Obrigatória. Lisboa: Ministério da Educação/Direção Geral da Educação (DGE). https://www. dge.mec.pt/sites/default/files/Curriculo/ Projeto_Autonomia e Flexibilidade/perfil dos_alunos.pdf

Moreira, J. (2010). Portefólio do Professor. Porto: Porto Editora.

Riviere (2003). Desarrollo y educación: el papel de la educación en el diseño del desarrollo humano. En Obra escogidas, vol II. Metarrepresentación y semiosis. Madrid: Editorial Médica Panaamericana.

Varela F. (2006). Conocer. Las ciencias cognitivas: tendencias y perspectivas. Cartografía de las ideas actuales. Barcelona: Gedisa

Vitón de Antonio, M.J. (2013). Diálogos con Raquel. Praxis Pedagógicas y reflexión de saberes para el desarrollo educativo en la diversidad cultural. Madrid: Editorial Popular. 